DOI: $10.47456 / k r k r . v 1 i 4.31859$

\title{
Educação do campo: uma história de luta e resistência
}

Field education: a story of fight and resistance

Silvanete Pereira dos Santos

Resumo: Esse artigo objetiva apresentar uma breve discussão sobre a historicidade da educação do campo no Brasil. Acrescenta-se a esse histórico três últimos grandes eventos no campo da pedagogia da alternância e da educação do campo de modo geral. Traz as considerações do segundo Encontro Nacional de Educadores e Educadoras da Reforma Agrária (II ENERA), do aniversário dos 50 anos do Movimento Educacional Proporcional do Espírito Santo (MEPES), precursor da pedagogia da alternância no Brasil, e os apontamentos do Seminário Internacional dos 50 anos da Pedagogia da Alternância no Brasil.

Palavras-chave: Educação do Campo. Pedagogia da Alternância. Movimentos sociais do Campo.

Abstract : This article aims to present a brief discussion about the historicity of the Brazilian's Rural Education. It adds, to this record, the last three major events in the field of the Pedagogy of Alternation and, in a general sense, to the Rural Education historical itself. It brings considerations of the second National Conference of the Agrarian Reform Educators (II ENERA), also the 50 th anniversary of the Espírito Santo's Proportional Educational Movement (MEPES), precursor of Brazilian's Pedagogy of Alternation and the notes to the International Workshop of Brazilian's 50 years Pedagogy of Alternation. Keywords: Rural Education. Pedagogy of Alternation. Social movements in the countryside

\section{Introdução}

Historicamente, a escola destinada aos camponeses foi reduzida a um modelo de escola urbana no campo, que desconsidera a materialidade das vivências e da identidade desse grupo como sujeitos sociais de direito.

A Educação do Campo surge do processo de luta dos movimentos sociais, pois ela nasceu como crítica à realidade da educação brasileira, particularmente à educação destinada aos povos do campo. A pedagogia da alternância destacase neste contexto e se diversifica em múltiplas concepções, distribuídas nas mais variadas práticas de Educação do Campo no Brasil.

No percurso de luta política por um projeto popular de desenvolvimento para o meio rural, a Educação do Campo foi inserida na agenda das políticas públicas, tendo como base a luta social, a organização e a vida dos camponeses. 
Dentre as diferentes práticas pedagógicas, fica evidente a formação mediada pela alternância no processo didático, desenvolvido por algumas instituições e movimentos sociais. Dentre eles temos: as Escolas Famílias Agrícolas, o Movimento dos Trabalhadores Sem Terra e algumas universidades federais. Destacam-se as atividades do Programa Nacional da Reforma Agrária (PRONERA), que possibilitaram, no cenário nacional, o espaço para o debate teórico e prático e a experiência apresentada pelo MEC destinada ao Programa de Apoio à Formação Superior em Licenciatura em Educação do Campo (PROCAMPO). Atualmente temos cerca de 42 Licenciaturas em Educação do Campo no Brasil.

\section{O contexto do campo brasileiro}

O campo brasileiro historicamente foi marcado pela ideia de lugar atrasado. Essa forma de pensar é imbuída da ideologia dominante que desconsidera a diversidade de sujeitos e relações sociais que o permeiam. Essa concepção faz parte da lógica do capital que o entende apenas como o espaço da produção e do latifúndio. ${ }^{1}$

Segundo Medeiros (2012), o latifúndio brasileiro tem sua origem a partir da colonização. A metrópole precisava extrair da colônia a produção de bens necessários para a manutenção da coroa portuguesa. Para isso, foram criadas as sesmarias ${ }^{2}$ que, na história brasileira, vieram acompanhadas da tentativa de escravizar primeiro os índios, e, após o fracasso no processo de escravização indígena, houve a escravização dos africanos. As sesmarias atraíram também muitos portugueses pobres que vinham em busca de melhores condições de vida. Ao chegar, tomavam posse de um pedaço de terra indiscriminadamente.

\footnotetext{
1 "O termo latifúndio, de origem latina, era usado na Roma Antiga para referir-se às extensões de terra controladas pela aristocracia e passou a ser utilizado para designar grandes propriedades de terra em geral" (MEDEIROS, 2012, p. 445).

2 Em 1375, foi estabelecida, em Portugal, a Lei das Sesmarias, seu objetivo era ajudar no avanço da agricultura que se encontrava abandonada em virtude das batalhas internas e da peste negra. Essa lei mais tarde foi adaptada para funcionar no Brasil. Segundo a Lei das Sesmarias, se o proprietário não fertilizasse a terra para a produção e a semeasse, esta seria repassada a outro agricultor que tivesse interesse em cultivá-la. Somente aqueles que tivessem algum laço com a classe dos nobres portugueses em Portugal, os militares ou os que se dedicassem à navegação e tivessem obtido honrarias que lhes garantissem o mérito de ganhar uma sesmaria tinham o direito de recebê-la (INFOESCOLA, 2012).
} 
O fim das sesmarias se deu com o advento da independência. Por certo tempo, o país ficou sem uma legislação que regulamentasse as concessões de terra, até a aprovação da Lei de Terras. Segundo Medeiros (2012, p. 445),

Essa legislação consagrou o regime de uso de terra que vinha da colônia: predomínio de grandes unidades, com uso abundante de mão de obra (escrava num primeiro momento, livre no final do século XIX), voltadas para cultivos destinados ao mercado externo - café, então principal produto da pauta de exportações e carro-chefe da economia nacional, cana-deaçúcar, algodão e outros -, ou para a pecuária extensiva, no caso de terras não utilizadas pela agricultura de exportação e mais distantes dos portos. Essas propriedades eram marcadas também pelo poder dos grandes proprietários, poder que se estendia aos que habitavam seus arredores e aos municípios, por meio do controle das Câmaras.

No momento atual, o modelo de desenvolvimento que concebe a existência do latifúndio é marcado pelo esvaziamento do campo por meio do êxodo rural, da negação do campesinato, do crescimento e expansão do agronegócio, da produção para a exportação, do uso extensivo de agrotóxico e do controle das sementes geneticamente manipuladas, dentre outros fatores fortemente contestados pelos Movimentos Sociais. A visão capitalista hegemônica de acesso à terra

[...] defende a ideia de que o Brasil já resolveu seu "problema agrário"; portanto, não há necessidade de uma Reforma Agrária do tipo clássico. Do ponto de vista do capitalismo, agora em sua fase de dominação pelo capital financeiro e pelas empresas transnacionais, de fato, não há necessidade de democratização da propriedade da terra como fator indutor do desenvolvimento do mercado interno e das forças produtivas no campo [...] (STEDILE, 2012, p. 664).

Os Movimentos Sociais recolocam o campo no cenário das políticas, tendo como base um modelo de desenvolvimento e de uma concepção de campo, em oposição à ideia hegemônica baseada no latifúndio e no agronegócio. Nesse sentido, Fernandes (2008) compreende o conceito de campo como uma totalidade na qual são desenvolvidas as várias dimensões da existência humana. Parte da visão de território como um espaço de produção da vida. 
Ao falarmos de território, é importante compreendermos que esse conceito é muitas vezes utilizado como instrumento de dominação das comunidades rurais pelo controle social dos modelos de desenvolvimento apresentados pelo capital. Neste trabalho, o território está sendo compreendido como um espaço de "[...] totalidade, multidimensionalidade, escolaridade e soberania. Portanto, é impossível compreender este conceito sem conceber as relações de poder que determinam a soberania" (FERNANDES, 2008, p. 52).

A ideia de território como totalidade refere-se ao entendimento dele como um todo integrado, porém não como uno. Cada território é uma totalidade multidimensional, que é determinada pelas relações sociais. Dessa forma, cada sujeito poderá criar as referências de seu território. Dentro dele estão as várias dimensões que o constituem: política, social, econômica e geográfica, dentre outras. Daí decorre a ideia da multiterritorialidade.

O território como um espaço multidimensional e multiterritorial evidencia a existência do território material e imaterial. "O território material constitui-se nos espaços físicos, enquanto os imateriais, nos espaços sociais por meio de pensamentos, conceitos, teorias e ideologias", que apresentam entre si uma relação de indissociabilidade (FERNANDES, 2008, p. 55). As construções e ações humanas no território material são sustentadas pelo universo simbólico da linguagem, ou seja, por um conjunto de leis, normas, teorias e ideologias, dentre outras, que constituem seu referencial.

As questões agrárias no Brasil, de acordo com Fernandes (2008), aparecem divididas entre duas compreensões de campo: o território camponês, que se auto-organiza para a subsistência como forma de potencializar todas as dimensões da vida dos seus sujeitos; e o território do agronegócio, que tem sua organização na produção de mercadorias para a exportação. Enquanto este apresenta paisagens homogêneas, monocultura e pouca presença do elemento humano, aquele apresenta uma paisagem heterogênea, caracterizada pela presença de pessoas.

Cada um desses territórios é representado por um paradigma específico. O camponês é norteado pelo paradigma da questão agrária que se transformou no novo desafio de "[...] reconstrução das possibilidades de superação do modo 
capitalista de produção. Na manutenção dessa perspectiva, os Movimentos Sociais camponeses são alguns dos poucos espaços, no qual se acredita nessa possibilidade" (FERNANDES, 2008, p. 44). O paradigma do capitalismo agrário, no qual situa o território do agronegócio, pauta-se na concentração de poder expresso em terra, dinheiro e tecnologia. Enquanto um representa o problema da concentração de poder mediado pelo capital, com o crescimento da desigualdade pela exclusão dos camponeses do acesso à "terra, capital e tecnologia", o outro se ocupa em travar uma luta que denuncie a "violência da exclusão e da expropriação".

O conceito de agronegócio é carregado da ideologia do capitalismo agrário, com a intenção de mascarar os velhos problemas da questão agrária mediante a utilização de um novo termo. Para Fernandes (2008, p. 48), o agronegócio:

[...] é também uma construção ideológica para tentar mudar a imagem latifundista da agricultura capitalista. O latifúndio carrega em si a imagem da exploração, do trabalho escravo, da extrema concentração de terra, do coronelismo, da subserviência, do atraso político e econômico.

Nota-se que a imagem do agronegócio é uma construção ideológica que tem o objetivo de maquiar o viés da concentração predatória, expropriadora e excludente da agricultura capitalista. Essa nova roupagem possibilitou a expansão da territorialidade do capital, aumentando o seu poder sobre o território e as relações sociais, perpetuando o sistema de opressão.

O processo ideológico que permeia o território do agronegócio atua como ferramenta de defesa e proteção do capital, a partir da premissa da extensa produtividade e da geração de riquezas. Torna-se o referencial de produção por excelência e, portanto, intocável. Se o uso social da terra está atrelado à ideia de produção, então o discurso da Reforma Agrária fica deslocado desse contexto. O agronegócio é utilizado para fortalecer o capital pela dominação da terra, da tecnologia e das políticas de desenvolvimento.

O discurso ideológico da agricultura patronal criou um processo de mercantilização da Reforma Agrária, fazendo com que o acesso à terra "[...] seja por meio das relações de mercado, de compra e venda. O controle da 
propriedade da terra é um dos trunfos do agronegócio. É fundamental que a terra esteja disponível para servir à lógica rentista" (FERNANDES, 2008, p. 50).

A concentração de terras nas mãos de poucos coloca o Brasil no cenário de desigualdade e desequilíbrio entre o rural e o urbano. A má distribuição da terra tem gerado conflitos e motivado a luta por Reforma Agrária. Stedile (2012, p. 657) diz que "Reforma Agrária é um programa de governo que busca democratizar a propriedade da terra na sociedade e garantir o seu acesso, distribuindo-a a todos que a quiserem fazer produzir e dela usufruir". Na perspectiva dos Movimentos Sociais, a posse da terra passa pela sua democratização e pela eliminação do latifúndio. Stedile ressalta que a questão agrária no imaginário popular, amplamente propagada pelos mecanismos midiáticos, compreende a expressão Reforma Agrária "[...] apenas como sinônimo de desapropriação de alguma fazenda e da política de assentamentos rurais [...]" (STEDILE, 2012, p. 663). Essa visão esvazia a luta pela terra do aspecto político da oposição ao atual modelo de desenvolvimento.

Essa visão superficial e equivocada do processo de recampesinato vinculada à mídia brasileira é resultado da ação do território imaterial (ideológico) do capitalismo, que consolida a sua territorialidade, mediante a destruição dos camponeses. Nesse sentido, percebemos que a ação dos Movimentos, por meio da luta pela terra, representa uma política de reafirmação do território camponês, haja vista que ele necessita da redistribuição da terra para produção da vida de seus sujeitos. Além disso, esse é um direito e uma questão de justiça social.

Os Movimentos defendem "[...] o conceito de território como espaço de vida e multidimensional que explicita o seu sentido político e as relações de poder necessárias para configurá-las" (FERNANDES, 2008, p. 58). É com essa compreensão de campo e de território que os povos do meio rural, organizados em movimentos, partiram para o enfrentamento da exclusão e da expropriação geradas pelo território capitalista, na luta pela construção de uma escola do campo e para o campo.

Mészáros (2008, p. 27) expressa que "[...] é necessário romper com a lógica do capital se quisermos contemplar a criação de uma alternativa educacional significativamente diferente" e que seja instrumento de luta que 
recoloque o campo na agenda pública do país, bem como uma proposta de educação e de desenvolvimento que supere a lógica da exclusão e que coloque em confronto dois projetos diferentes de desenvolvimento, conforme o quadro a seguir:

Quadro 1 - Comparativo de projetos de desenvolvimento para o campo brasileiro

\begin{tabular}{|c|c|}
\hline CAMPO DO AGRONEGÓCIO & CAMPO DA AGRICULTURA CAMPONESA \\
\hline Monocultura & Policultura \\
\hline Paisagem homogênea e simplificada & Paisagem heterogênea e complexa \\
\hline $\begin{array}{l}\text { Produção para } \\
\text { (preferencialmente) }\end{array}$ & $\begin{array}{l}\text { Produção para o mercado interno e para a } \\
\text { exportação }\end{array}$ \\
\hline $\begin{array}{l}\text { Cultivo e criação onde predominam as } \\
\text { espécies exóticas }\end{array}$ & $\begin{array}{l}\text { Cultivo e criação onde predominam as } \\
\text { espécies nativas e da cultura local }\end{array}$ \\
\hline Erosão genética & $\begin{array}{l}\text { Conservação e enriquecimento da diversidade } \\
\text { biológica }\end{array}$ \\
\hline $\begin{array}{l}\text { Tecnologia de exceção com elevados } \\
\text { níveis de insumos externos }\end{array}$ & $\begin{array}{l}\text { Tecnologia apropriada, apoiada no saber } \\
\text { local, com base no uso da produtividade } \\
\text { biológica primária da natureza }\end{array}$ \\
\hline Competitividade e eliminação de emprego & Trabalho familiar e geração de emprego \\
\hline $\begin{array}{l}\text { Concentração de riquezas, aumento da } \\
\text { miséria e da injustiça social }\end{array}$ & $\begin{array}{l}\text { Democratização das riquezas } \\
\text { desenvolvimento local }\end{array}$ \\
\hline Exxodo rural e periferias inchadas & $\begin{array}{l}\text { Permanência, resistência na terra e migração } \\
\text { urbano-rural }\end{array}$ \\
\hline $\begin{array}{l}\text { Campo do trabalho assalariado } \\
\text { decréscimo) }\end{array}$ & Campo do trabalho familiar e da reciprocidade \\
\hline Paradigma da educação rural & Paradigma da Educação do Campo \\
\hline Perda da diversidade cultural & $\begin{array}{l}\text { Riqueza cultural diversificada - festa, danças, } \\
\text { poesias, músicas, jogos }\end{array}$ \\
\hline AGI & LTURA \\
\hline
\end{tabular}

Fonte: Molina; Jesus (Orgs.), 2004, p. 85.

A seguir, discutiremos o processo de construção da Educação do Campo no Brasil, o projeto de campo que está sendo construído pelos sujeitos do território camponês, bem como a compreensão da educação como um significativo instrumento da classe trabalhadora na luta contra-hegemônica.

\section{Educação do campo e movimentos sociais}

Este tópico busca situar historicamente a Educação do Campo no Brasil no contexto das lutas por uma educação de qualidade, envolvendo questões desde as condições básicas de vida dessa população excluída, até a formação integral desses sujeitos que habitam, trabalham e vivem no e do campo, na busca de sua libertação, como sujeitos de direitos. 
Houve avanços significativos que marcaram e solidificaram a luta dos Movimentos Sociais, não só por educação, mas por condições de vida digna. Tal luta mobilizou a população camponesa em prol de uma escola e de uma educação que fosse de fato do campo e para o campo. Conforme apresenta Santos (2009, p. 37), essa educação nasceu das reivindicações dos Movimentos Sociais que, por meio de sua atuação, fizeram significativas transformações na sociedade. A autora enfatiza que essa trajetória constitui uma política dos camponeses que "[...] traz o debate acerca do conceito de campo e educação, perpassado pelo Estado, na acepção gramsciana, como 'cenário de conflito social, complexo e múltiplo, denominado guerra de posição' [...]".

A Educação do Campo representa os interesses da classe trabalhadora, bem como seu direito de ser reconhecida como povo, como sujeitos coletivos de direito. Esse conceito supera a mera demanda por escola. Com ele, os Movimentos Camponeses apresentam o desejo de construir uma nova ordem social e uma ruptura do modelo hegemônico de construção e organização da vida em sociedade.

O conceito específico de Educação do Campo foi afirmado pelos Movimentos Sociais por ocasião da primeira Conferência Nacional por uma Educação Básica do Campo, realizada em 1998, na qual se afirma, em seu documento base, que:

Utilizar-se-á a expressão Campo, e não mais ao usual meio rural, com o objetivo de incluir no processo da conferência uma reflexão sobre o sentido atual do trabalho camponês e das lutas sociais e culturais dos grupos que hoje tentam garantir a sobrevivência desse trabalho (KOLLING; NERY; MOLINA, 1999, p. 26).

A opção política pela expressão campo, em substituição à expressão rural, não se trata apenas de uma mudança de nomenclatura. Representa o projeto político de Educação do Campo e de desenvolvimento presente na luta dos Movimentos Sociais camponeses. Conforme Arroyo (1999, p.18), "Qualquer proposta e ação educativa só acontecem se enxertada em uma nova dinâmica social". O autor chama a atenção para o fato de que é necessário estar atento aos novos sujeitos que estão se construindo, os novos valores que a dinâmica 
social do meio rural está fazendo surgir. Portanto, a expressão campo representa a compreensão de uma ruptura da concepção política atual.

A ação dos Movimentos Sociais recoloca o campo no espaço do debate político, no enfrentamento de uma visão romântica na qual os camponeses são vistos como um grupo culturalmente atrasado, uma espécie em extinção. "No modelo de desenvolvimento que vê o Brasil apenas como mais um mercado emergente, predominantemente urbano, camponeses e indígenas são vistos como espécie em extinção [...]" (KOLLING; NERY; MOLINA, 1999, p. 21). Sendo esse o pensamento hegemônico, é compreensível que, para esta lógica, não exista a necessidade real de políticas públicas para um grupo que deixará de existir. Aí está a relevância da luta que vem sendo travada, nos últimos anos, por uma educação para esses sujeitos.

Segundo Santos (2009, p. 38), a Educação do Campo traz em sua gênese três desafios:

[...] primeiro deles é assegurar o direito ao acesso dos camponeses ao conhecimento, como instrumento político fundamental para a ruptura da sua histórica condição de subordinação frente ao capital. O segundo desafio diz respeito ao direito à diferença. Que os novos sujeitos [...] sejam reconhecidos pelas suas práticas e pelo acúmulo de conhecimentos construído. [...]. O terceiro desafio é trabalhar um novo projeto que, no campo da elaboração e da disseminação do conhecimento historicamente acumulado pela humanidade, rompa com o paradigma hegemônico do capital na educação $[\ldots]$.

As ações dos Movimentos fomentaram um processo de discussão acerca do direito à educação e à escola para os povos do campo, pois constataram a necessidade de melhor compreender o momento histórico vivido e o processo de luta construído. Nesse contexto, organizaram, em 1997, o I Encontro Nacional de Educadores/as da Reforma Agrária que ficou conhecido como I ENERA. Esse encontro foi realizado nas instalações da Universidade de Brasília em pareceria com a Conferência Nacional dos Bispos do Brasil (CNBB), com o Fundo das Nações Unidas para a Infância (UNICEF) e com a Organização das Nações Unidas para a Educação, a Ciência e a Cultura (UNESCO). Conforme relata Santos (2009, p. 39), 
A partir daí passam a ser reconhecidos como sujeitos de direitos, tanto por alguns organismos internacionais de defesa dos direitos humanos e do direito humano à educação e à cultura, como UNICEF e UNESCO, quanto por um organismo religioso, também de reconhecida luta por direitos humanos, como é o caso da CNBB.

Ainda segundo Santos (2009, p.39), o I ENERA serviu como mola propulsora de novos debates e reflexões em torno da necessidade da educação para o meio rural. Esse encontro propiciou "[...] forte mobilização social em torno do direito à educação dos camponeses [...]". A partir de então, as ações ganharam proporção nacional, provocando e criando espaços coletivos de debates em todo território brasileiro. Os Estados começaram a organizar grupos para incidir de forma política na questão da Educação do Campo na conjuntura do país.

O I ENERA pontuou a luta por escolas públicas do campo e para o campo, bem como a preocupação com a qualidade da educação para esse público e, portanto, um interesse particular em refletir sobre o projeto político pedagógico e a participação dos povos do meio rural, no debate e na luta por uma escola pública de qualidade e de um processo de desenvolvimento para o país que respeitasse o direito de todos.

Como resultado da inserção política dos Movimentos Sociais do campo relacionados à educação, nasce a necessidade de pensar em políticas públicas que assegurem o direito dos camponeses à formação. Os Movimentos propõem uma ação em âmbito federal para garantir educação para aqueles que lutavam por Reforma Agrária. Então surgiu a proposta da criação do Programa Nacional de Educação na Reforma Agrária (PRONERA).

Segundo Santos (2009), a capacidade de mobilização política e os apoios recebidos por parte da sociedade e de algumas instituições, como, por exemplo, as universidades presentes no III Fórum das Instituições de Ensino Superior, pautaram-se, para o governo federal, na "[...] necessidade de criação de um programa específico para atender às exigências educacionais nas áreas da Reforma Agrária" (p. 43). Por meio dessa mobilização, foi criado, em 16 de abril 
de 1998, o PRONERA 3 no governo de Fernando Henrique Cardoso, vinculado ao Ministério Extraordinário da Política Fundiária sob a Portaria de n. ${ }^{\circ} 10$.

Ainda como reflexo do I ENERA, os Movimentos Sociais se organizaram para a realização da I Conferência Nacional por uma Educação Básica do Campo - I CNEC, antecipada por uma significativa e cuidadosa preparação, que aconteceu em Luziânia-GO, em julho de $1998,{ }^{4}$ sob a coordenação de cinco instituições: CNBB, MST, UNICEF, UNESCO e UnB. Foi a I Conferência Nacional por uma Educação Básica do Campo contando com a participação de 974 pessoas de todas as regiões do Brasil.

No documento final da I CNEC, os Movimentos Sociais estabeleceram dez compromissos e desafios:

1 - vincular as práticas de educação básica do campo com o processo de construção de um projeto popular de desenvolvimento, 2 - propor e viver novos valores culturais, 3 valorizar as culturas do campo, 4 - fazer mobilizações em vistas da conquista de políticas públicas pelo direito à educação básica do campo; 5 - lutar para que todo o povo tenha acesso à alfabetização, 6 - formar educadores e educadoras do campo, 7 - produzir uma proposta de educação básica do campo, 8 envolver as comunidades nesse processo, 9 - acreditar na nossa capacidade de construir o novo, 10 - implementar as propostas de ação dessa conferência (KOLLING; NERY; MOLINA, 1999, p. 92-94).

Ao pensar o campo como um lugar de sujeitos de direitos, podemos afirmar que a I Conferência teve como objetivos: "[...] ajudar a recolocar o rural, e a educação que a ele se vincula na agenda política do país [...]" e que é possível e necessário pensar/implementar um projeto de desenvolvimento para o Brasil, que inclua milhões de pessoas que atualmente vivem no campo e que a educação, além de um direito, faz parte desta estratégia de inclusão" (CALDART, 2002, p. 22).

Uma conquista importante nessa trajetória foi a aprovação das Diretrizes Operacionais para a Educação Básica nas Escolas do Campo, aprovadas em 3

3 O PRONERA tem como objetivo: "Fortalecer a educação nas áreas de Reforma Agrária estimulando, propondo, criando, desenvolvendo e coordenando projetos educacionais, utilizando metodologias voltadas para a especificidade do campo [...]" (INCRA, Portaria $\mathrm{N}^{\circ} 282,2004$ ). 4 A I Conferência Nacional por uma Educação Básica do Campo (I CNEC) aconteceu nos dia 27 a 30 de julho de 1998. 
de abril de 2002, sob a Resolução n 1/2002 da Câmara de Educação Básica do Conselho Nacional de Educação. Sem dúvida, essa conquista se constituiu em mais uma ferramenta na luta pela Educação do Campo que, por meio dos Movimentos Sociais e sindicais e das organizações populares, ampliou o debate sobre a escola, buscando vinculá-lo ao conceito de Educação do Campo, colocando-a como política pública no enfrentamento dos antagonismos da luta de classe.

As práticas dos movimentos e organizações vão se consolidando e apresentam a educação como um direito e a escola como uma instituição comprometida com a transformação social, porque traz em suas práticas conteúdos da realidade. As Diretrizes Operacionais destacam a importância da vinculação da escola à realidade dos sujeitos, conforme o Art. $2^{\circ}$, parágrafo único: "A identidade da escola do campo é definida pela sua vinculação às questões inerentes à sua realidade [...]". Além disso, destaca ainda no Art. $5^{\circ}$ que os saberes historicamente construídos pelos sujeitos que a constituem devem ser considerados no Projeto Político Pedagógico.

Nesse cenário, a escola que segue o modelo capitalista em que o mundo urbano se impõe ao mundo rural passa a ter outros significados, sendo um deles a sua ligação com a luta pela terra e a construção de relações que envolvem terra, trabalho e meio social cooperativo e solidário, uma das finalidades básicas da nova educação. A escola passa a ser também espaço de formação, dentro dessa luta maior. Como afirma Caldart (2004, p. 91), "[...] a escola é um lugar fundamental de educação do povo, exatamente porque se constitui como um tempo e um espaço de processos socioculturais, que interferem significativamente na formação e no fortalecimento dos sujeitos sociais que dela participam".

A escola é a principal agente na formação de intelectuais. Nesse sentido, ao instaurar a luta por escola, por formação adequada aos povos do campo, os movimentos reivindicam o direito de formar seus sujeitos, os novos intelectuais das classes subalternas. "[...] a escola é a principal agência, na sociedade civil, de formação de intelectuais. De modo especial, preocupa-lhe a preparação de 
intelectuais de novo tipo, organicamente ligados às classes subalternas" (SOARES, 2000, p. 191, grifo do autor).

O Art. 4, em consonância com a proposta dos Movimentos, aponta para algumas questões pertinentes a uma nova ordem social, ao situar a escola do campo como um "[...] espaço público de investigação e articulação de experiências e estudos direcionados [...] para o desenvolvimento social, economicamente justo e ecologicamente sustentável" (RESOLUÇÃO CNE/CEB No 1//2002).

É importante notarmos como as diretrizes denotam a participação incisiva dos Movimentos Sociais em sua constituição. Percebemos isso na estruturação de seus artigos e no conteúdo que em muito expressa a luta por uma Educação Básica do Campo. Esse fato é resultado de um amplo processo de participação dos diferentes sujeitos, em toda mobilização para que a legitimidade das reivindicações dos camponeses organizados pudesse ser considerada no debate e na construção de uma política pública para a educação do meio rural.

Em relação a essa conquista, Santos (2009, p. 45) destaca que as Diretrizes Operacionais para a Educação do Campo são, sem dúvida:

Uma conquista conceitual no território da institucionalidade. A
Educação do Campo como conceito é admitido na referida
Resolução, conceito esse que se afirma na contraposição à
educação rural como fruto de intenso debate internamente à
Câmara da Educação Básica, nas audiências públicas
realizadas quando da sua elaboração, mas inegavelmente, um
debate que não aconteceria não fosse a presença (inédita) dos
camponeses debatendo naquele espaço (grifo do autor).

Outra ação de mobilização e luta dos Movimentos Sociais em prol da Educação foi o Seminário Nacional por uma Educação Básica do Campo, realizado em novembro de 2002, no Centro Comunitário Athos Bulcão, na Universidade de Brasília. A organização desse evento contou com a participação do Movimento dos Trabalhadores Rurais Sem Terra (MST), da Confederação Nacional dos Trabalhadores da Agricultura (CONTAG), do Movimento dos Pequenos Agricultores (MPA), do Movimento dos Atingidos por Barragens (MAB), do Movimento de Mulheres Trabalhadoras Rurais (MMTR) e da Pastoral da Juventude Rural (PJR). O Seminário teve cinco objetivos: 1) dar continuidade 
à discussão nascida na I CNEC de 1998; 2) aprofundar a discussão sobre políticas públicas a partir das Diretrizes Operacionais para a Educação Básica do Campo; 3) avaliar os impactos produzidos pelo PRONERA na Educação do Campo; 4) socializar práticas e reflexões sobre a construção do projeto político e pedagógico das escolas do campo; e 5) consolidar compromissos e definir propostas de ação do conjunto das organizações participantes do seminário (KOLLING; CERIOLI; CALDART, 2002, p. 123).

Um dos marcos significativos do Seminário de 2002, dentre outros, é seguramente a inclusão, no documento final, ${ }^{5}$ da reivindicação da criação de um órgão específico para articular as questões ligadas à Educação do Campo que a instituísse enquanto política pública. Segundo Santos (2009, p. 47):

O seminário, pela força de sua representatividade, no seu ato de encerramento recebe um enviado do Governo Lula e a ele apresenta o documento final - "Educação do Campo Declaração 2002", que, entre as propostas de ação em relação ao tema, reivindica a criação, por parte do MEC, de uma instância especifica para tratar de Educação do Campo.

Foi nesse Seminário que os movimentos fizeram a opção da substituição do termo Educação Básica do Campo pela terminologia Educação do Campo. A argumentação para tal mudança foi apresentada em 2002 com a participação dos movimentos do campo.

Temos uma preocupação prioritária com a escolarização da população do campo. Mas, para nós, a educação compreende todos os processos sociais de formação das pessoas como sujeitos de seu próprio destino. Nesse sentido, educação tem relação com cultura, com valores, com jeito de produzir, com formação para o trabalho e para a participação social (KOLLING; CERIOLI; CALDART, 2002, p. 19).

Essa é uma opção política no contexto da luta pelo direito à educação, entendendo que compreende não apenas a Educação Infantil, o Ensino Fundamental, Médio e Profissional, mas também a Educação Superior. Está presente a ideia de educação como um bem público que necessita universalizarse para se tornar acessível a todos.

5 O documento final do Seminário Nacional ficou conhecido como "Educação do Campo - Declaração $2002 "$. 
Entre as discussões destacadas pelo Seminário, trazemos algumas reflexões sobre a intenção da Educação do Campo a partir do pensamento de Roseli Salete Caldart (2002). A autora destaca que esta é uma luta pelo direito de todos à educação como política pública, bem como nos convida a lutar por uma educação que respeite o jeito de educar e o modo de construir que formem as pessoas como sujeitos de direitos. Caldart (2002) apresentou alguns pontos relevantes que foram debatidos no Seminário. Dentre eles: a Educação do Campo identifica uma luta pelo direito de todos à educação; os sujeitos são os sujeitos do campo; ela se faz vinculada às lutas sociais do campo e ao diálogo entre os diferentes sujeitos; ela se identifica com a construção de um projeto educativo. Discuti-la significa também incluir a construção de escolas do campo, os educadores e as educadoras são sujeitos da Educação do Campo.

Ao se colocarem os povos do campo como cidadãos de direitos, afirmase que é necessário compreender que a educação é uma proposta que se faz no diálogo entre os diferentes sujeitos, portanto tal educação deve ser pensada como um espaço plural, de forma a se comunicar com a diversidade cultural, geográfica, política etc. que permeia o contexto rural brasileiro. Nesse sentido, o diálogo demarca a identidade dos povos do campo e suas diferenças e que tais diferenças não os descaracterizam enquanto povo do território camponês.

A trajetória transcorrida no processo de luta tem mostrado que as diferenças são na verdade traços marcantes da identidade. O importante é compreender que, na diversidade de povos do mesmo território, conforme assinala Caldart (2002, p. 31), "[...] estas diferenças não apagam nossa identidade comum: somos um só povo; somos a parte do povo brasileiro que vive no campo e que historicamente tem sido vítima da opressão e da discriminação, que é econômica, política, cultural".

No ano seguinte à realização do Seminário de 2002, conquista-se outro marco importante no percurso histórico das lutas, a criação do Grupo Permanente de Trabalho de Educação do Campo (GPT). Este foi atrelado à Secretaria de Educação Básica do Ministério da Educação e Cultura (MEC), vinculado à Coordenação da Diretoria de Ensino Médio. Santos (2009, p. 47) cita que, em novembro de 2003, O GPT organiza "[...] um seminário para debater [...] 
as referências para uma Política Pública de Educação do Campo [...]" e como resultado o Ministério da Educação publica o Caderno "Referências para uma Educação do Campo".

Em continuidade às reflexões e ações políticas propostas no primeiro Seminário em 2002, a mobilização desencadeada pela Articulação Nacional propôs a organização do Seminário "Uma articulação Política para a Educação do Campo", realizado pela Câmara dos Deputados em junho de 2004. Segundo Clarice Santos (2009, p. 49), "[...] a importância daquele Seminário esteve associada à redefinição do tema da II CNEC, era necessário [...] que assegurasse esse tema: a legitimidade de uma política pública de Educação do Campo". Em seguida, realizou-se, em agosto de 2004 em Luziânia-GO, a II Conferência Nacional de Educação do Campo (II CNEC), com o tema: "Por uma Política Pública de Educação do Campo". A Conferência contou com a participação de 1.100 representantes de vários movimentos sociais e sindicais e organizações sociais de trabalhadores do campo de todo o país; universidades, ONGs e Centros Familiares de Formação por Alternância; secretarias estaduais e municipais de educação e outros órgãos do poder público. A II CNEC, em sua declaração final, organizou o documento em três partes: o que defendemos, o que queremos e o que vamos fazer.

A II CNEC contribuiu para criar a Coordenação Geral de Educação do Campo vinculada à Secretaria de Educação Continuada, Alfabetização, Diversidade e Inclusão (SECADI), ${ }^{6}$ em junho de 2004, no âmbito do Ministério da Educação e Cultura. Tal secretaria está vinculada à Coordenação Geral de Educação do Campo. "A criação [...] significa a inclusão na estrutura federal de uma instância responsável, especificamente, pelo atendimento dessa demanda ${ }^{7}$ a partir do reconhecimento de suas necessidades e singularidades" (HENRIQUES et al., 2007, p. 12). A coordenação foi uma conquista importante na história da Educação do Campo. Por meio dela e de outras ações, os movimentos têm colocado a Educação do Campo na pauta da política pública brasileira.

6 Em 2004, utilizava-se a sigla SECAD, somente em 2011 passou a chamar SECADI com a passagem da Secretaria da Inclusão sob a administração da SECAD.

7 A demanda da Educação do Campo. 
Um ano depois de sua criação, a SECADI realizou seminários regionais em todos os estados da federação, com intuito de refletir sobre a Educação do Campo em âmbito nacional.

No ano de 2006, o movimento conta com mais uma conquista significativa para o avanço e desenvolvimento da Educação do Campo, que foi o reconhecimento dos diferentes tempos formativos da Pedagogia da Alternância por meio do Parecer CNE/CEB N. ${ }^{\circ}$ 1/2006 aprovado em $1^{\circ}$ de fevereiro, cujo relator foi Murílio de Avellar Hingel. O parecer reconhece os dias letivos para a aplicação da Pedagogia de Alternância nos Centros Familiares de Formação por Alternância (CEFFAs). Conforme afirma o relatório, essa pedagogia é uma ferramenta importante para a Educação do Campo diante da conjuntura atual da realidade brasileira.

O parecer destaca a relevância dessa pedagogia para o campo e afirma que ela tem se mostrado como a melhor alternativa para a educação no Ensino Fundamental, Médio e na Educação Profissional de nível médio, sobretudo pela capacidade que tem de articular os diferentes espaços de formação: a comunidade, a escola e a família.

\section{Das conquistas: rumo às licenciaturas}

Ainda em 2006, foi criado o Programa de Apoio à Formação Superior em Licenciatura em Educação do Campo (PROCAMPO) por meio da SECADI/MEC. Esse programa tem como objetivo "[...] apoiar a implementação de cursos regulares de licenciatura em Educação do Campo nas instituições públicas de ensino superior de todo o país [...]" (PORTAL MEC, 2012). A atuação do Programa visa, especificamente, a formação de educadores para atuarem nos anos finais do Ensino Fundamental e Médio nas escolas do campo.

Essa ação é de suma importância na história da Educação do Campo, no sentido de garantir o acesso à formação de nível superior para os povos desse território e, em particular, por atuar no âmbito da formação superior pública. Sabemos que os sujeitos do campo, historicamente, foram excluídos do acesso à educação pública de qualidade em todos os níveis de ensino. Contudo, nos últimos anos, nas séries iniciais do Ensino Fundamental, isso tem sido menos 
traumático, porém, no que se refere à educação de nível médio e profissional e de nível e superior, a discrepância em relação ao que é oferecido para a população urbana é ainda maior.

Além disso, o PROCAMPO tem uma particularidade que em muito tem contribuído para a garantia do direito à educação pública no contexto camponês, que é a organização dos cursos de licenciatura a partir da Pedagogia da Alternância. Ao organizar-se em regime de alternância, contribui para que muitos jovens e adultos possam conciliar o trabalho nas propriedades rurais com a formação superior. Outra contribuição extremamente significativa é o fato de que a alternância possibilita um processo de investigação da realidade das comunidades rurais, em interação com as diversas teorias que permeiam o espaço acadêmico. Essa dinâmica tem favorecido a interação e a troca de saberes entre os diferentes sujeitos que compõem o complexo território da Educação do Campo.

O PROCAMPO iniciou com uma experiência piloto com as licenciaturas em Educação do Campo, conforme apresentado na introdução deste trabalho, contando com a participação da Universidade Federal da Bahia (UFBA), Universidade Federal de Minas Gerais (UFMG), Universidade Federal de Sergipe (UFS) e Universidade de Brasília (UnB). Atualmente, houve uma ampliação da oferta e participação de universidades, totalizando 30 que oferecem licenciaturas em Educação do Campo. Dentre elas, cinco estão com vestibular permanente. Sobre esse tema, retomaremos a discussão no terceiro capítulo deste trabalho.

De acordo com Molina e Sá (2011), as ações previstas pelo PROCAMPO trazem para o centro a classe trabalhadora.

A experiência desta Licenciatura em Educação do Campo traz o desafio de uma perspectiva contra-hegemônica dentro da Universidade, tendo como referência a presença da classe trabalhadora do campo. Este desafio se traduz nas formas de organização do trabalho pedagógico pela exigência de que o processo educativo não se desvincule das questões relacionadas à disputa dos modelos de desenvolvimento rural e de sociedade (MOLINA; SÁ, 2011, p. 43). 
As universidades, por meio das Licenciaturas em Educação do Campo, em diálogo permanente com os Movimentos Sociais, propõem um modo revolucionário de ser universidade, ao instituir o Projeto Político com base nas matrizes formadoras da escola do campo.

Para o atual modelo de desenvolvimento que vê o território camponês como um espaço social e cultural em extinção, a Educação do Campo não faz sentido aos olhos de muitos. Portanto, é importante questionar qual educação está sendo oferecida aos camponeses e qual a concepção de educação que está presente nessa proposta. A oferta de cursos de licenciatura específica para a formação do professor que atua na escola rural instaura um novo elemento no âmbito da discussão teórica, que nos permite refletir a respeito da extensão e profundidade do termo "Educação Superior", articulando-a com as questões da Educação do Campo.

A contribuição significativa da luta dos Movimentos, pela inserção da classe camponesa no Ensino Superior, está em consonância com a construção do olhar sobre o direito à educação. A luta por Reforma Agrária objetiva mais do que o acesso à terra, demanda também o fortalecimento da agricultura camponesa que representa a forma de viver e produzir a vida de um povo. Além disso, ela fortalece a luta pela educação pública e o desenvolvimento social, cultural e econômico do campo. Portanto, a luta pela garantia da educação superior é mais uma forma de o povo camponês mostrar ao país que ele existe e sabe resistir à força hegemônica excludente, bem como lutar por seus direitos.

A proposta de formação das licenciaturas, em consonância com 0 pensamento de Frigotto (2008, p. 28), postula-se na profissionalização a partir da "[...] centralidade do trabalho como criador da condição humana" em contraponto à lógica dominante de alienação do trabalho como mercadoria e força de trabalho.

Mais um avanço foi somado às conquistas da Educação do Campo, ao ser publicada a Resolução CNE/CEB N. 2/2008, que estabelece diretrizes complementares, normas e princípios para o desenvolvimento de políticas públicas de atendimento da Educação Básica do Campo. Essa Resolução compõe as bases legais das licenciaturas em Educação do Campo. Nota-se que 
as definições tomadas na II CNEC continuam sendo pautadas pelos Movimentos Sociais que têm se mobilizado na perspectiva de avançar na conquista de políticas públicas efetivas, que atuem no fortalecimento e desenvolvimento do processo educativo para o meio rural. Conforme cita o Art. $1^{\circ}$ :

$\S 1^{\circ}$ A Educação do Campo, de responsabilidade dos Entes Federados, que deverão estabelecer formas de colaboração em seu planejamento e execução, terá como objetivos a universalização do acesso, da permanência e do sucesso escolar com qualidade em todo o nível da Educação Básica.

$\S 2^{\circ} \mathrm{A}$ Educação do Campo será regulamentada e oferecida pelos Estados, pelo Distrito Federal e pelos Municípios, nos respectivos âmbitos de atuação prioritária.

$\S 3^{\circ} \mathrm{A}$ Educação do Campo será desenvolvida, preferentemente, pelo ensino regular (RESOLUÇÃO CNE/CEB No. 2/2008, p. 1).

Em 2010, foi publicado o Decreto 7352, no governo do presidente Luiz Inácio Lula da Silva, que dispõe sobre a política de Educação do Campo e o Programa Nacional de Educação na Reforma Agrária (PRONERA). O Decreto regulamenta a oferta da Educação Superior para a população do meio rural conforme o Art. $1^{\circ}$ :

A política de educação do campo destina-se à ampliação e qualificação da oferta de educação básica e superior às populações do campo, e será desenvolvida pela União em regime de colaboração com os Estados, o Distrito Federal e os Municípios [...] (BRASIL, Decreto 7352 de novembro de 2010) (grifo nosso).

Reconhece como sujeitos do campo os grupos que são afirmados na luta dos Movimentos Sociais expressos no Art. $1^{\circ}$, inciso $1^{\circ}$ que "[...] produzam suas condições materiais de existência a partir do trabalho no meio rural". Como escola do campo, o decreto optou pela definição expressa pelo IBGE "escola do campo: aquela situada em área rural, [...] ou aquela situada em área urbana, desde que atenda predominantemente a populações do campo".

Além disso, foram consideradas turmas do campo aquelas que funcionam em áreas rurais, porém são anexos de escolas com sede em área urbana. $A$ novidade dessa questão é que, sendo reconhecidas como do campo, faz-se necessário que o Projeto Político Pedagógico leve em consideração tal especificidade. 
O Art. $5^{\circ}$ que trata sobre a formação de professores no inciso $1^{\circ}$ assegura que as licenciaturas poderão ser organizadas a distância quando se fizer necessário. $\mathrm{O}$ inciso $2^{\circ}$ reconhece a alternância como uma das pedagogias que atende às especificidades da Educação do Campo, bem como ressalta, no inciso $3^{\circ}$, que "As instituições públicas de ensino superior deverão incorporar nos projetos políticos-pedagógicos de seus cursos de licenciatura os processos de interação entre o campo e a cidade e a organização dos espaços e tempos da formação [...]" (BRASIL, Decreto 7352/2010).

Outro aspecto importante, presente no Art. $6^{\circ}$, é a garantia das condições materiais e pedagógicas para a realização do processo educativo referente à formação inicial e continuada dos profissionais da educação. Isso remete a uma reflexão a respeito da importância dos materiais didáticos na construção da identidade dos sujeitos, uma vez que a ideologia dominante expressa nos livros tem reforçado a estratégia de dominação sobre as classes dominadas.

Os recursos didáticos, pedagógicos, tecnológicos, culturais e
literários destinados à educação do campo deverão atender às
especificidades e apresentar conteúdos relacionados aos
conhecimentos das populações do campo, considerando os
saberes próprios das comunidades, em diálogo com os saberes
acadêmicos e a construção de propostas de educação no campo
contextualizadas (BRASIL, Decreto 7352/2010).

Em tempos mais recentes, um marco importante foi a realização do segundo ENERA em fevereiro de 2014 em Luziânia - GO. O segundo Encontro Nacional de Educadores e Educadoras da Reforma Agrária, teve como objetivo, entre outros, a necessidade de realizar análise da política educacional brasileira, de modo que, estas possam refletir as práticas educativas das área de reforma agrária, formular coletivamente o projeto educativo no contexto histórico atual, situando-o no âmbito do projeto da reforma agrária popular, encontrar caminhos que possam fortalecer a participação e envolvimento dos estudantes nos assentamentos e acampamentos e denunciar a precarização da educação pública (MST, 2014, p.8).

Decorreu do encontro, a elaboração de um manifesto no qual, os educadores e educadoras demarcaram a necessidade da continuidade da luta 
pela educação do campo pública e de qualidade, desde a educação infantil ao nível superior. Entre os compromissos previstos no documento destacamos:

1. Seguir lutando por uma sociedade justa, democrática e igualitária, sem exploração do trabalho e da natureza, com Reforma Agrária [...].

3. Combater o modelo do agronegócio que representa doenças, morte e destruição da natureza e dos povos do campo, das florestas e das águas [...].

5. Trabalhar pela agroecologia como matriz tecnológica, produção de conhecimento [...].

6. Combater a privatização da educação pública em todas as suas formas, seguir na defesa de uma educação pública desde a educação infantil até a universidade [...].

8. Combater a indústria cultural capitalista que produz um modo de vida consumista e individualista.

9. Seguir denunciando que FECHAR ESCOLA É CRIME! [...].

10. Trabalhar pela alfabetização e políticas públicas de EJA [...].

11. Defender para todos os trabalhadores e as trabalhadoras do campo e da cidade, uma educação emancipatória [...].

12. Seguir na construção de uma escola ligada à vida das pessoas, que tome o trabalho socialmente produtivo, a luta social, a organização coletiva, a cultura e a história como matrizes organizadoras [...].

14. Participar das lutas dos trabalhadores e das trabalhadoras da educação por condições dignas de trabalho, valorização profissional e formação adequada (SÍTIO MST, 2015 grifo do autor).

Outro marco importante foi a realização do Seminário Internacional dos

50 anos do MEPES, realizado em outubro de 2018. Nesse seminário, participaram representantes dos Centro de Formação por Alternância (CEFFAS) de 14 estados brasileiros e 12 países. Como resultado do seminário produziu-se um documento intitulado "Carta de Piuna" com os seguintes compromissos:

O Projeto Político Pedagógico que adota a Pedagogia da Alternância surge das experiências de resistência como direito à educação [...] vinculada aos interesses dos sujeitos do campo. Projeto que se contrapõe ao modelo de educação reprodutivista, posicionando-se em prol de uma educação emancipatória dos seus sujeitos e pela transformação do meio;

O modelo de produção no campo, organizado pelo agronegócio é denunciado por suas graves consequências expropriatórias de sujeitos, concentração de terras e capital. Esta, portanto, não é a alternativa possível aos povos do campo aqui reunidos;

A Educação dos CEFFAs [...] está vinculada a um projeto de campo, com defesa da reforma agrária, a soberania alimentar, a 
soberania hídrica e energética e a agroecologia como matriz tecnológica, os direitos a cultura, a saúde, a comunicação, lazer, financiamentos públicos, em consonância com os pilares meios dos CEFFAs (gestão associativa e alternância como sistema educativo) e, com os pilares fins (formação integral e desenvolvimento do meio);

Não podemos deixar de destacar a realização do Seminário dos 50 anos da Pedagogia da Alternância em setembro de 2019, em Salvador-BA, intitulado "Pedagogia da Alternância no Brasil - 50 anos - Juventude e Educação, Saberes e Fazeres da Formação em Alternância no Brasil”, no qual foram discutidos os seguintes temas: gestão associativa e comunitária, pedagogia da alternância, formação integral e desenvolvimento do meio.

Definiu-se como marco nesse seminário, que a Pedagogia da Alternância e seus pilares, tem se mostrado como uma pedagogia com potencial emancipar, tanto para os estudantes em formação quanto para suas comunidades, assim como para os demais sujeitos que constituem a alternância.

\section{Considerações finais}

Olhando para o breve histórico descrito, notamos que a Educação do Campo no panorama brasileiro é um caminho de construção contínuo e requer que estejamos conscientes, o mais amplamente possível, de como ocorreu esse processo histórico, de modo que se efetive como um elemento político. Para isso, é fundamental o papel dos movimentos sociais e das universidades que se identificam com o projeto, na luta constante do trabalho educativo na perspectiva gramsciana, nos diversos espaços, nos quais imperam a concepção hegemônica de educação.

Compreendemos que a luta por educação do campo continua na pauta dos movimentos sociais e sindicais do campo, dos CEFFAS e outros que se colocaram nessa tarefa de construir uma Educação do Campo que respeite as necessidades e especificidades dos sujeitos do campo.

Nesse quesito, destacamos a continuidade dessa luta, citando como exemplo, o parecer da pedagogia da alternância que foi apresentado ao Conselho Nacional de Educação, no dia 06 de julho de 2020. Contudo, o parecer 
não recebeu a provação do conselho que propôs a retirada desse documento de pauta para ser apresentado em outro momento.

\section{Referências Bibliográficas}

ARROYO, Miguel Gazalez. A educação básica e o movimento social do campo. In: . FERNANDES, Bernardo Mançano (Org.). A educação básica e o movimento social do campo. Brasília: Vozes, 1999, p. 18.

BRASIL. Conselho Nacional de Educação Câmara de Educação Básica. Resolução CNE/CEB 1, de 3 de abril de 2002. Estabelece as Diretrizes Operacionais para a Educação Básica nas Escolas do Campo. Diário Oficial da União, Brasília, 9 abr. 2002. Seção 1, p. 32.

. Resolução CNE/CEB n 2, de 24 de abril de 2008. Estabelece diretrizes complementares, normas e princípios para o desenvolvimento de políticas públicas de atendimento da Educação Básica do Campo. Diário Oficial da União, Brasília, 24 abr. 2008. Seção 1, p. 81.

Conselho Nacional de Educação. Parecer CNE/CEB N. ${ }^{\circ}$ 1/2006. Dias letivos para a aplicação da Pedagogia de Alternância nos Centros Familiares de Formação por Alternância (CEFFA). Diário Oficial da União, Brasília, 15 mar. 2006.

Decreto $\mathrm{n}^{\circ} 7352$, de 5 de novembro de 2010. Dispõe sobre a política de educação do campo e o Programa Nacional de Educação na Reforma Agrária (PRONERA). Diário Oficial da União, Brasília, 5 nov. 2010, p. 1.

. MINSTÉRIO DA EDUCAÇÃO E CULTURA. Procampo. Disponível em: http://portal.mec.gov.br/index.php?option=com content\&view=article\&id=12394 :procampo-de-apoio-a-formacao-superior-em-licenciatura-em-educacao-docampo-procaMpo-1\&catid=320:procampo\&ltemid=679 . Acesso em: 29 jun. 2012.

CALDART, Roseli Salete. Por uma Educação do Campo: traços de uma identidade. In: KOLLING, Edgar; CERIOLI, Paulo Ricardo; CALDART, Roseli Salete (Orgs.). Educação do campo: identidade e políticas públicas. v. 4. 2. ed. Brasília: Articulação Nacional por uma Educação do Campo, 2002. (Coleção por uma Educação do Campo). p. 25-36.

CALDART, Roseli Salete. Pedagogia do movimento sem terra. São Paulo: Expressão Popular, 2004.

FERNANDES, Bernardes Mançano. Educação do campo e território camponês. In:__. SANTOS, Clarice Aparecida. Por uma educação do campo: campo, políticas e educação. Brasília: NEADA/INCRA, 2008, p.39-66.

FRIGOTTO, Gaudêncio. Educação, crise do trabalho assalariado e do desenvolvimento: teorias em conflito. In: . FRIGOTTO, Gaudêncio (Org.). 
Educação e crise do trabalho: perspectivas de final de século. 9. ed. Petrópolis: Vozes, 2008, p. 25-54.

HENRIQUES, R. et. al. (Org.). Educação do campo: diferenças mudando paradigmas. Brasília: Cadernos Secad 2, 2007 (INFOESCOLA, 2012).

KOLLING, Edgar Jorge; NÉRY, Israel José; MOLINA, Mônica Castagna. (Orgs.). Por uma educação básica do campo. v.1. 3. ed. Brasília: Fundação Universidade de Brasília, 1999.

KOLLING, Edgar; CERIOLI, Paulo Ricardo; CALDART, Roseli Salete (Orgs.). Educação do campo: identidade e políticas públicas. v. 4. 2. ed. Brasília: Articulação Nacional por uma Educação do Campo, 2002. (Coleção por uma Educação do Campo).

MOVIMENTO DOS TRABALHADORES SEM TERRA. Manifesto do II ENERA. Disponivel em: https://mst.org.br/2015/10/01/educadores-da-reforma-agrarialancam-manifesto-pela-educacao-durante-o-2-eneral. Acesso em: 20 julho 2020.

MEDEIROS, Leonildes Servolo de. Latifúndio. In:_. CALDART, Roseli Salete et al. Dicionário da Educação do Campo. Rio de Janeiro: Expressão Popular, 2012, p. 445-4451.

MEDEIROS, Maria Osanette de. Novos olhares, novos significados: a formação de educadores do campo. Brasília, 2012. Tese (Doutorado em Educação. Universidade de Brasília, Brasília, 2012.

MÉSZÁROS, István. A educação para além do capital. São Paulo: Boitempo, 2008.

MOLINA, Mônica Castagna; JESUS, Sônia Meire Santos Azevedo (Orgs.). Contribuições para a construção de um projeto de educação do campo. Brasília,DF: Articulação Nacional "Por uma educação do Campo", v. 5, 2004.

; SÁ, Laís Mourão. A licenciatura do campo da Universidade de Brasília: estratégias político-pedagógicas na formação de educadores do campo. In:__. Licenciaturas em educação do campo. Belo Horizonte: Autêntica,

2011, p. 35-61.

SANTOS, Clarice Aparecida dos. Educação do campo e políticas públicas no Brasil: a instituição de políticas públicas pelo protagonismo dos movimentos sociais do campo na luta pelo direito à educação. Brasília. 2010. Dissertação (Mestrado em Educação). - Universidade de Brasília, Brasília, 2010.

SOARES, Rosemary D. O "Estado ampliado" e a escola. In:__. A concepção gramsciana do estado e o debate sobre a escola. ljuí: Unijuí, 2000, p. $189-208$. 
STEDLE, João Pedro. Reforma Agrária. In: . CALDART, Roseli Salete et al. Dicionário da Educação do Campo. Rio de Janeiro: Expressão Popular, 2012, p. 657-666.

TRINDADE, Domingos Rodrigues. A Licenciatura em Educação do Campo da UnB: a experiência da inserção orientada na escola do campo e na comunidade. Brasília. 2011. Dissertação (Mestrado em Educação). - Universidade de Brasília, Brasília, 2011.

\section{Sobre os Autores}

Silvanete Pereira dos Santos

sil.si101@gmail.com

Doutora em Educação e professora da Unversidade Federal do Espírito Santo Campus - Goiabeiras no Curso de Licenciatura em Educação do Campo 